\title{
BMJ Open Socioeconomic variables and fracture risk in children and adolescents: a population-based study from northern Sweden
}

\author{
Erik Hedström (D) , ${ }^{1}$ Sead Crnalic, ${ }^{1}$ Antonia Kullström, ${ }^{1}$ Ingeborg Waernbaum ${ }^{2}$
}

To cite: Hedström E, Crnalic S, Kullström A, et al. Socioeconomic variables and fracture risk in children and adolescents: a population-based study from northern Sweden. BMJ Open 2021;11:e053179. doi:10.1136/ bmjopen-2021-053179

- Prepublication history and additional supplemental material for this paper are available online. To view these files, please visit the journal online (http://dx.doi.org/10.1136/ bmjopen-2021-053179).

Received 08 May 2021 Accepted 27 September 2021

Check for updates

(c) Author(s) (or their employer(s)) 2022. Re-use permitted under CC BY. Published by BMJ.

${ }^{1}$ Department of Surgical and Perioperative Sciences, Umeå University, Umeå, Sweden

${ }^{2}$ Department of Statistics, Uppsala University, Uppsala, Sweden

Correspondence to Dr Erik Hedström; erik.hedstrom@umu.se

\section{ABSTRACT}

Objectives Previous studies have investigated the association between socioeconomic characteristics and fractures among children, producing different results. In a population-based study, we previously found an increased risk of fractures among children living in an urban municipality compared with rural municipalities. This study aimed to evaluate the importance of socioeconomic variables for the incidence of fractures among 0-17year olds.

Setting, design and outcome measure We present a longitudinal, observational study of a population 0-17 years of age. Data from an injury database were linked with additional socioeconomic data for the population at risk. These were 55758 individuals residing within the primary catchment area of a regional hospital in northern Sweden. Using the number of fractures as the outcome, we fitted a generalised linear mixed model for a Poisson response with socioeconomic variables at the family level as independent variables while controlling for age, sex and place of residence.

Results We found a significant association between higher levels of family income and the risk of fracture, rate ratio $1.40(1.28-1.52) p<0.001$ when comparing the highest income quintile to the lowest as well as the number of siblings and the risk of fracture. Children with one or two siblings had a rate ratio of 1.28 (1.19-1.38) $p<0.001$ when compared with children with no siblings. Parents' educational level and having a single parent showed no significant association with fractures. The previously observed association between municipalities and fracture risk was less pronounced when taking family-level socioeconomic variables into account. Conclusion Our results indicate that children from families with higher income and with siblings are at greater risk of sustaining fractures.

\section{BACKGROUND}

Fractures are common in children and adolescents. The incidence has consistently been shown to be influenced by age and sex. ${ }^{1-3}$ Previous studies have examined relationships between socioeconomic factors and injuries. Some studies use measurements of socioeconomic status at the individual or family level, ${ }^{45}$ while the majority are ecological

\section{STRENGTHS AND LIMITATIONS OF THIS STUDY}

$\Rightarrow$ Socioeconomic variables were collected at the individual/family level, the original source being tax records, something that is lacking in many previous studies.

$\Rightarrow$ There were relatively few cases with missing values.

$\Rightarrow$ Using a well-established database and examining the outcome within a well-defined catchment area should ensure that the results are less sensitive to some types of confounding.

$\Rightarrow$ Not all fractures occurring within the catchment area have been registered in the database, minor fractures may not have warranted a visit to the hospital ED, others may have been misdiagnosed, and some cases may have been lost in the registration process.

$\Rightarrow$ Using a different variable for 'place of residence', with smaller and more homogenous geographical areas may have yielded other results concerning the variability between areas.

studies in which geographical units such as parishes or electoral wards are described and compared with respect to socioeconomic variables and injury rates. ${ }^{6-13} \mathrm{~A}$ few studies have analysed the importance of socioeconomics at both the individual and area levels in multilevel designs. ${ }^{1415}$

A number of studies have reported an association between measures of social vulnerability or deprivation and injuries. Higher rates of injuries resulting in visits to emergency departments (EDs) have been reported in areas with lower socioeconomic status defined by the Townsend index ${ }^{614}$ and in areas with a higher percentage of people living below the poverty line. ${ }^{7}$ Stark and colleagues found a higher rate of fractures in deprived neighbourhoods than in affluent neighbourhoods. ${ }^{9}$ Overpeck and colleagues reported a greater number of medically attended injuries among children in single-parent households. ${ }^{16}$ Other studies have found no significant association ${ }^{11} 13$ or 


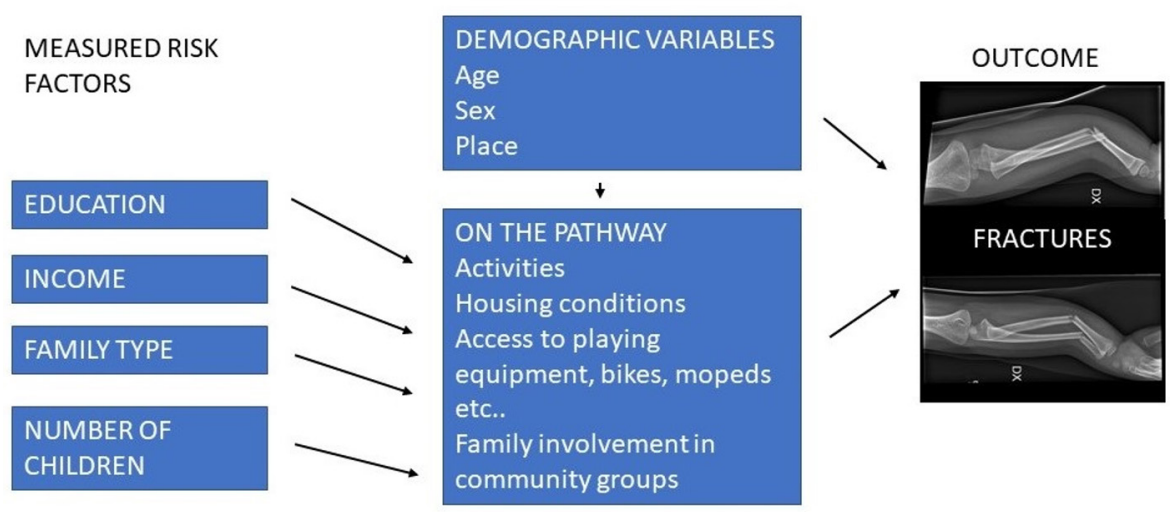

Figure 1 Conceptual model of the relationship between variables and outcome.

even reverse associations with increased rates of injuries among children from more affluent circumstances. ${ }^{5} 8$

In our previous work, we described the dependences of sex and age on fractures among children and adolescents in Umeå and its surrounding municipalities. We investigated the incidence in different municipalities within the catchment area and found that children living in the four most rural municipalities, namely, Nordmaling, Robertsfors, Bjurholm and Vindeln (NRBV), had significantly fewer fractures than their peers in the more densely populated municipality of Umeå. ${ }^{17}$

This longitudinal, observational study aims to explore the relationships between socioeconomic variables such as parents' educational level, employment status and income as well as the number of siblings and having a single parent and the risk of fracture in children aged 0-17 years in northern Sweden. The outcome was any fracture leading to a visit to the ED at Umeå University Hospital, which is the sole hospital serving the catchment area. A conceptual model of the relationship between our measured variables and the outcome is illustrated in figure 1 .

\section{MATERIALS AND METHODS}

The population at risk was defined as those aged 0-17 years of age living in Umeå and its surrounding municipalities between 1998 and 2010. Because of the longitudinal design of this study, where both explanatory variables and the outcome were measured on a yearly basis, the composition of the population changed over time. Each year, some children were born into, or moved into the population while other children reached adulthood or moved out of the catchment area. This means individuals had varying exposure time, that is, the number of years that they were part of the population at risk. The average population at risk for the time period was 29817. The characteristics of the municipalities within the catchment area have been described in our previous work. ${ }^{17}$

The Swedish Initiative for Research on Microdata in the Social And Medical Sciences (SIMSAM) is aimed at promoting innovative, interdisciplinary research using microdata. The SIMSAM database includes data from a number of Swedish registries. The fracture data used in this study originally came from the injury database (IDB) at Umeå University Hospital. Socioeconomic data were collected from Statistics Sweden (SCB). The IDB data included information on injuries sustained by patients seeking care at the ED of Umeå University Hospital. Patients with suspected fractures are generally referred to the hospital for diagnosis and treatment. Fractures were in most cases confirmed radiographically. ${ }^{1} \mathrm{~A}$ small percentage of fractures, such as nose and rib fractures, may have been diagnosed clinically. The quality and validation of IDB data have been described in detail in a previous publication. ${ }^{1}$ For this study, the data included date of fracture, sex, age and a unique personal identifier, which allowed us to link fracture data with the data from SCB. Data from SCB included the same personal identifier and a household identifier, which made it possible to link children and parents/households. For adults, the administrative data contained information on annual employment status, disposable income, highest attained educational level and civil status each year. For these variables, the percentage of missing values ranged between $0.1 \%$ and $0.6 \%$. Missing values were excluded from the regression analysis. To control for possible bias due to missing values, we also performed a multiple imputation of the data after our initial analysis. Age, income and number of siblings were originally quantitative, discrete variables but were treated as categorical in the final regression analysis. Income was adjusted for family size and divided into quintiles. Other variables were divided into categories. The outcome for the analysis was the number of fracture events per year.

The project was delayed for reasons beyond our control and this is why the data are somewhat dated at the time of this report.

\section{Patient and public involvement}

No patients were involved in the design, conduct or reporting of this study. Nor have they so far been involved in the dissemination plans of the research. Results will be communicated to the public with help of the communications department at Umeå University. 
Table 1 Distribution of socioeconomic variables

\begin{tabular}{|c|c|c|c|}
\hline Independent variable & & Children with no fracture & Children with fracture \\
\hline \multirow[t]{2}{*}{ Number of siblings } & Mean number (SD) & $2.18(1.10)$ & $2.30(1.03)$ \\
\hline & Missing & $24(<0.01 \%)$ & $2(<0.01 \%)$ \\
\hline \multirow{2}{*}{ Family income } & Median income SEK in thousands & 363 & 379 \\
\hline & Missing & $184(0.4 \%)$ & $12(0.2 \%)$ \\
\hline \multirow{2}{*}{ Family type } & Single parent & $8074(16.5 \%)$ & $1019(15.1 \%)$ \\
\hline & Missing & $191(0.4 \%)$ & $16(0.2 \%)$ \\
\hline \multirow[t]{3}{*}{ Parents' level of education } & $\begin{array}{l}\text { Both parents with primary school } \\
\text { education only }\end{array}$ & $1108(2.3 \%)$ & $96(2.2 \%)$ \\
\hline & $\begin{array}{l}\text { One or both parents with upper } \\
\text { secondary school education but no } \\
\text { university level education }\end{array}$ & 18147 (37.0\%) & $2810(41.6 \%)$ \\
\hline & Missing & $18(0.3 \%)$ & $783(1.4 \%)$ \\
\hline
\end{tabular}

Percentages within each column and variable.

SEK, Swedish Kronor.

\section{Statistical analysis}

The outcome, that is, number of fractures/year, is quantitative and possibly zero-inflated; accordingly, a Poisson regression model was first fitted. In addition, to take into account the repeated measurement for individuals, a generalised linear mixed effects model (glmm) was used, incorporating a random effect for the individuals and fixed effects for the demographic and socioeconomic risk factors under study.

For each individual, we used yearly records from linked administrative data from 1998 to 2010. The response variable, number of fractures, and demographic and socioeconomic predictor variables are described in table 1. A zero-inflated generalised linear mixed model for count data was fitted taking into account the dependence structure of the data. All analyses were performed in the $\mathrm{R}$ statistical software. ${ }^{18}$ We used the glmmTMB package and the glmmTMB function for the model fit. The CIs for the risk factors were obtained by the delta method using package msm and function deltamethod. Imputation of missing data for a supplementary analysis was performed using the $\mathrm{R}$ software, package mice. ${ }^{18}$ Here, the default regression options were used for imputation of the missing values for the variables; number of siblings, family type, parents level of education and family income.

\section{RESULTS}

A total of 55758 individuals $0-17$ years of age were included in the study population. The mean exposure time per individual was 7 years. There were 28675 boys (51\%) and 27083 girls (49\%). One or more fractures were sustained by 6750 individuals (12\%) during the study period. In this group of children with fractures, $4006(59.3 \%)$ were boys. Table 1 shows the distribution of values for socioeconomic variables between the group of children with no fracture and fracture. The table also shows the number of missing values per variable.

In the fitted Poisson regression model, there was a significant association between sex, age and fracture incidence. The results are displayed in table 2, including estimates of the regression coefficient $\beta$, rate ratios (RRs) with $95 \%$ CIs and $\mathrm{p}$ values. Boys had an RR of 1.44 (1.36-1.52) in comparison to girls. There was a significant association between family income level and fracture incidence. Those in families with the highest income quintile had an RR of 1.40 (1.28-1.52) in comparison to the lowest quintile families (table 2). Children with siblings had a significantly higher rate of fractures than those who lived in single-child households, RR 1.28 (1.18-1.38) for twothree-children families and RR 1.35 (1.24-1.47) if there were three or more children. There was no significant association between the number of fractures and parents' educational attainment or single-parent households. There was no statistically significant association between municipality and fractures. Children living in Umeå had an RR of 1.08 (1.00-1.16) compared with children living in most rural municipalities.

Our repeated regression analysis including imputed values did not affect the observed associations or the significance of results Online supplemental table 1 shows the descriptives using imputed values, and in online supplemental table 2 , the regression model was refitted with the complete data set after imputation. 
Table 2 Results of Poisson regression

\begin{tabular}{|c|c|c|c|c|}
\hline & Estimated $\beta$ & $\mathbf{R R}$ & $95 \% \mathrm{Cl}$ for $\mathrm{RR}$ & $P$ value \\
\hline Age $0-5$ years & Reference & & & \\
\hline $12-17$ years & & 1.89 & 1.77 to 2.03 & $<0.001$ \\
\hline Sex (boys, girls as reference) & 0.361 & 1.44 & 1.36 to 1.52 & $<0.001$ \\
\hline Umeå & 0.0766 & 1.08 & 1.00 to 1.16 & 0.051 \\
\hline Income first quintile & Reference & & & \\
\hline Second quintile & 0.1043 & 1.11 & 1.03 to 1.20 & 0.009 \\
\hline Third quintile & 0.2043 & 1.23 & 1.13 to 1.33 & $<0.001$ \\
\hline Siblings (one to two) & 0.248 & 1.28 & 1.19 to 1.38 & $<0.001$ \\
\hline Siblings (three or more) & 0.302 & 1.35 & 1.24 to 1.47 & $<0.001$ \\
\hline Single parent (cohabiting as reference) & -0.035 & 0.97 & 0.90 to 1.03 & 0.304 \\
\hline Both parents only primary education & Reference & & & \\
\hline No parent with university education & 0.200 & 1.22 & 0.98 to 1.53 & 0.081 \\
\hline One parent with university education & 0.148 & 1.16 & 0.93 to 1.45 & 0.198 \\
\hline
\end{tabular}

Rate ratios $(\mathrm{RR})$ with $95 \% \mathrm{Cl}$ and $\mathrm{p}$ values. For categorical values, the $\mathrm{RR}$ is interpreted such that the given $\mathrm{RR}$ is relative to the reference category within that variable. NRBV is a grouping of the four most rural municipalities, namely, Nordmaling, Robertsfors, Bjurholm and Vindeln.

\section{DISCUSSION}

A higher rate of fractures among boys and variations with growth are well described in many previous reports, and our findings support these studies. ${ }^{2319}$

There was a consistent increase in RR with increasing family income. This could be because children from families with more economic resources more often have accessibility to playing equipment such as trampolines, bicycles and skis. As children become older and start participating in organised sports, the cost of membership fees, equipment, etc may also influence the child's possibilities depending on the family's economic resources. In a study from the Swedish Research Council for Sport Science, it was reported that children from families with greater economic capital were more likely to participate in sports. ${ }^{20}$ As visits to the hospital ED were free of charge, we do not believe the association between fracture rates and income is explained by lower accessibility to healthcare services among low-income families.

In previous studies, there were conflicting associations between socioeconomic variables and injuries. Several studies have reported a correlation between injuries requiring medical attention, burns, poisonings and pedestrian injuries and measures of deprivation. ${ }^{461021-23}$ In an ecological study, Stark et al found that children living in deprived areas had a significantly higher fracture rate than those in affluent areas, ${ }^{9}$ and Menon et al reported an association between deprivation and fractures in adolescents. ${ }^{24}$ Two other studies from the UK found no association between fractures in general and measures of deprivation. ${ }^{813}$ However, Lyons et al did report higher rates of sports-related fractures in affluent areas. ${ }^{8}$ Ramaesh et al reported that children from more affluent households were more likely to sustain fractures in connection to sports, while children from more deprived families suffered more fractures from road traffic accidents, falls and blows. ${ }^{12}$ These seemingly contradictory findings probably reflect differences in context, age groups, injury types and choice of socioeconomic variables that define each study.

A reason why children with siblings appeared to be at higher risk of fractures could be because these kids interact with their peers and siblings a greater part of the day. It could also be that the types of interactions differ between siblings compared with non-siblings. Reading reported an increased risk of accident attendance in preschool children with an increased number of siblings. ${ }^{14}$ Other than this study, we are not aware of other studies that have reported the influence of the number of siblings on injury outcome.

We found no association between single-parent households and fractures. Overpeck et al reported an increased risk of medically attended non-fatal injuries among children from single-parent households. ${ }^{16}$ There are no 
other studies known to us investigating fracture rates that have used this variable. We found no association between parents' educational level and fractures. As in our previous study, we found a higher rate of fractures in Umeå than in the four most rural municipalities (NRBV), ${ }^{17}$ but the association was weaker and did not show statistical significance. This is explained by the inclusion of additional explanatory variables at the individual and family level that could have acted as confounders in the previous analysis. This finding does not rule out the importance of place and environment for the outcome. Using different variables at the area level or a different division of areas could have yielded different results. In a study by Eriksson et al, the authors investigated the association between social capital and injuries (not only fractures) in Umeå using a multilevel approach and found that some of the variance in child injuries was explained at the neighbourhood level, even if it was less than the proportion of variance explained at the household level. ${ }^{15}$ They also reported an increased incidence of all medically attended injuries in children (0-12 years) in families where no adult had higher (tertiary level) education compared with families where at least one adult had higher education. ${ }^{15}$ They found no association between income levels and injuries. These differences in associations compared with our results could be explained by the type of injuries that were chosen as outcome but may also have been influenced by the difference in age span.

In observational studies, it is not possible to come to conclusions about causal mechanisms that explain observed dependences, so this is a general limit of the study design. In retrospect, it would have been prudent to have used the activity at injury variable, which was part of the original IDB, in this data set. This could have added to our understanding of the associations between income levels, number of children and fractures. A division of fractures according to severity type may have offered further insights into differences between groups. For instance, if the difference in incidence between income groups was largely due to higher rates of high energy, high severity fractures such as spine, pelvic or femoral fractures this would add to the importance of observed differences.

We are also aware that not all fractures are accounted for in the data. Minor fractures may not have been properly diagnosed or may not have warranted a visit to the hospital ED. In our previous research, we found no indication that the distance to the ED significantly influences the rate of fractures. ${ }^{17}$ The number of fractures is also influenced by the completeness of data and accuracy in registration as has been discussed in our previous work. ${ }^{1}$ Our use of socioeconomic variables was limited by our understanding and experience using these variables. We would also like to acknowledge that there are many variables and plausible risk factors that we have no data on. Due to the age of data, our results may not accurately reflect the current rate of fractures in Umeå and its surroundings. Our previous results showed some variation in incidence over time. ${ }^{1}$ If changes have occurred in the population with respect to socioeconomic conditions, health or activities, this may have altered our results with use of more recent data.

A strength of this study is that it is population based within a well-defined catchment area. Socioeconomic variables, based on tax records, were collected at the individual family level and with very few individuals' missing data, which is rare in previous work. In some previous studies, data were inferred to the individual level from mean values at the area level, such as post codes or parishes. This may reflect a variability that exists at the area level but does not accurately reflect the impact of individual and family characteristics. We believe that our use of several socioeconomic variables to be a strength, as they may reflect different dimensions of socioeconomic status.

\section{CONCLUSIONS}

In a population-based study investigating the possible association between socioeconomic variables and fractures, while controlling for age and sex, we found that children from more affluent families in higher income quintiles had higher rates of fractures. Additionally, children with siblings had higher rates of fractures than children without siblings. The previously observed effect of place, with more fractures occurring in an urban municipality than in more rural municipalities, was no longer significant. From these results, it appeared that the association between socioeconomic individual/family level variables and fracture risk was stronger than the association between place of residence and fracture risk. To advance our knowledge and understanding further, future studies should ideally include timely and relevant information on the injury and injury event. Explanatory variables such as age, sex, activities, family characteristics and socioeconomic factors on the individual level need to be included. At the same time, we need to understand and consider the importance of environment and place. The choice of variables is determined by the research questions and will ultimately be limited by the resources available and the skills and expertise of the researchers involved. The formation of multidisciplinary research teams will likely contribute to the quality of future research.

Contributors We hereby confirm that all authors have made substantial contributions to this work. EH and IW were behind the conception and design of the work and the acquisition of data. EH, AK, SC and IW all contributed to the analysis and interpretation of the data. All authors were involved in the drafting and revision of the manuscript. All authors have approved the final version to be published and have agreed to be accountable for all aspects of the work in ensuring that questions related to the accuracy or integrity of any part of the work are appropriately investigated and resolved.

Funding This study was funded by Region Västerbotten (Västerbotten County) (FS 2.1.6-2408-18 RV-940639) and by Umeå University (FS 2.1.6-2408-18 RV-940639).

Competing interests None declared.

Patient consent for publication Not applicable.

Ethics approval Ethical approval exists under the heading 'Injuries in children and adolescents-a population-based study'. Dnr 2009-1407-31, Regional Ethics 
Committee Umeå. Ethical approval for the use of socioeconomic data in this study was granted within the SIMSAM project under the heading 'Childhood diseases and injuries in a social context'. Dnr: 2010-157-31, Regional Ethics Committee Umeå.

Provenance and peer review Not commissioned; externally peer reviewed.

Data availability statement Data may be obtained from a third party and are not publicly available. The data for this study is not available to the public. Data in the SIMSAM lab is stored on secure servers (off grid) in a room which can only be accessed by authorised staff. The ethical approval and the rules concerning use of the SIMSAM database require that data is not moved from the SIMSAM lab. Questions concerning the use of data and applications for use of data can be made to the steering group of the Umeå SIMSAM lab. https://www.umu.se/en/research/ infrastructure/umea-simsam-lab/.

Supplemental material This content has been supplied by the author(s). It has not been vetted by BMJ Publishing Group Limited (BMJ) and may not have been peer-reviewed. Any opinions or recommendations discussed are solely those of the author(s) and are not endorsed by BMJ. BMJ disclaims all liability and responsibility arising from any reliance placed on the content. Where the content includes any translated material, BMJ does not warrant the accuracy and reliability of the translations (including but not limited to local regulations, clinical guidelines, terminology, drug names and drug dosages), and is not responsible for any error and/or omissions arising from translation and adaptation or otherwise.

Open access This is an open access article distributed in accordance with the Creative Commons Attribution 4.0 Unported (CC BY 4.0) license, which permits others to copy, redistribute, remix, transform and build upon this work for any purpose, provided the original work is properly cited, a link to the licence is given, and indication of whether changes were made. See: https://creativecommons.org/ licenses/by/4.0/.

ORCID iD

Erik Hedström http://orcid.org/0000-0002-1700-8223

\section{REFERENCES}

1 Hedström EM, Svensson O, Bergström U, et al. Epidemiology of fractures in children and adolescents. Acta Orthop 2010;81:148-53.

2 Rennie L, Court-Brown CM, Mok JYQ, et al. The epidemiology of fractures in children. Injury 2007;38:913-22.

3 Bergman E, Lempesis V, Nilsson Jan-Åke, et al. Time trends in pediatric fractures in a Swedish City from 1950 to 2016. Acta Orthop 2020;91:598-604.

4 Engström K, Diderichsen F, Laflamme L. Socioeconomic differences in injury risks in childhood and adolescence: a nation-wide study of intentional and unintentional injuries in Sweden. Inj Prev 2002;8:137-42.

$5 \mathrm{Ni} \mathrm{H}$, Barnes P, Hardy AM. Recreational injury and its relation to socioeconomic status among school aged children in the US. Inj Prev 2002;8:60-5.

6 Laing GJ, Logan S. Patterns of unintentional injury in childhood and their relation to socio-economic factors. Public Health 1999;113:291-4.
7 Faelker T, Pickett W, Brison RJ. Socioeconomic differences in childhood injury: a population based epidemiologic study in Ontario, Canada. Inj Prev 2000;6:203-8.

8 Lyons RA, Delahunty AM, Heaven M, et al. Incidence of childhood fractures in affluent and deprived areas: population based study. BMJ 2000;320:149-49.

9 Stark AD, Bennet GC, Stone DH, et al. Association between childhood fractures and poverty: population based study. BMJ 2002;324:457-57.

10 Reimers A, Laflamme L. Neighbourhood social and socio-economic composition and injury risks. Acta Paediatr 2005;94:1488-94.

11 Reimers A-M, de Leon AP, Laflamme L. The area-based social patterning of injuries among 10 to 19 year olds. changes over time in the Stockholm County. BMC Public Health 2008;8:131-31.

12 Ramaesh R, Clement ND, Rennie L, et al. Social deprivation as a risk factor for fractures in childhood. Bone Joint $J$ 2015;97B:240-5.

13 Baker R, Orton E, Tata LJ, et al. Epidemiology of poisonings, fractures and burns among 0-24 year olds in England using linked health and mortality data. Eur J Public Health 2016;26:940-6.

14 Reading R, Langford IH, Haynes R, et al. Accidents to preschool children: comparing family and neighbourhood risk factors. Soc Sci Med 1999;48:321-30.

15 Eriksson M, Lindgren U, Ivarsson A, et al. The effect of neighbourhood social capital on child injuries: a gender-stratified analysis. Health Place 2019;60:102205-05.

16 Overpeck MD, Jones DH, Trumble AC, et al. Socioeconomic and racial/ethnic factors affecting non-fatal medically attended injury rates in US children. Inj Prev 1997;3:272-6.

17 Hedström EM, Waernbaum I. Incidence of fractures among children and adolescents in rural and urban communities - analysis based on 9,965 fracture events. Inj Epidemiol 2014;1:1-5.

18 R Foundation for Statistical Computing. R: A Language and Environment for Statistical Computing [program. Vienna, Austria: R Foundation for Statistical Computing, 2020.

19 Landin LA. Fracture patterns in children. Analysis of 8,682 fractures with special reference to incidence, etiology and secular changes in a Swedish urban population 1950-1979. Acta Orthop Scand Suppl 1983;202:1-109.

20 Dartsch C, Norberg JR, Pihlblad J, eds. Idrotten och (o)jämlikheten: i medlemmarnas eller samhällets intresse? Stockholm, Sweden, 2019.

21 Hippisley-Cox J, Groom L, Kendrick D, et al. Cross sectional survey of socioeconomic variations in severity and mechanism of childhood injuries in Trent 1992-7. BMJ 2002;324:1132-4.

22 Gilbride SJ, Wild C, Wilson DR, et al. Socio-Economic status and types of childhood injury in Alberta: a population based study. BMC Pediatr 2006;6:30.

23 Brown CE, Chishti P, Stone DH. Measuring socio-economic inequalities in the presentation of injuries to a paediatric A\&E department: the importance of an epidemiological approach. Public Health 2005;119:721-5.

24 Menon MRG, Walker JL, Court-Brown CM. The epidemiology of fractures in adolescents with reference to social deprivation. $J$ Bone Joint Surg Br 2008;90:1482-6. 